\title{
INFÂNCIA E EDUCAÇÃO AMBIENTAL: CONSTRUINDO AS TRILHAS DO BRINCAR CONSCIENTE
}

\section{CHILDHOOD AND ENVIRONMENTAL EDUCATION: BUILDING PATHS FOR CONSCIOUS PLAY}

\author{
Marta Regina Furlan de Oliveira* \\ ORCID: http://orcid.org/0000-0003-2146-2557 \\ Valéria Queiroz Furtado** \\ ORCID: http://orcid.org/0000-0003-0810-5598
}

\section{Resumo}

Este artigo traz experiências extensionistas do projeto "Educação Ambiental e Infância: reflexões e ações a partir de jogos e brinquedos confeccionados com material reciclável", desenvolvido pelos departamentos de Psicologia e de Educação da UEL Londrina e do Programa Universidade Sem Fronteiras (USF). Seu objetivo é refletir sobre o processo de confecção de jogos e brinquedos produzidos com materiais recicláveis e aplicação com crianças de um Centro de Educação Infantil, oportunizando situações formativas, lúdicas e interativas com estudantes de Psicologia e Pedagogia. A metodologia consistiu em estudo bibliográfico e relato de experiência baseados nas seguintes etapas: 1) Organização; 2) Preparação; 3) Elaboração e confecção de jogos e brinquedos recicláveis; 4) Aplicação com crianças de 4 e 5 anos. Os resultados evidenciaram a escassez de publicações científicas sobre o tema, assim como o potencial e a eficácia do uso de jogos confeccionados com materiais recicláveis, na promoção da educação ambiental com crianças pré-escolares.

Palavras-chave: Infância; Brincar; Reciclagem; Extensão.

Data recebimento: 03/09/2020

\begin{abstract}
This article presents experiences of the project "Environmental Education and Childhood: reflections and actions based on games and toys made with recyclable material" developed by the Psychology and Education departments of UEL Londrina and the University without Borders Program (USF). It aims at reflecting on the process of making games and toys produced with recyclable materials and using them with children from a Child Education Center, providing opportunities for training, playful and interactive situations with students from the Psychology and Education undergraduate courses. The methodology consisted of a bibliographic study and reports of experiences based on the following steps: 1) Organization; 2) Preparation; 3) Elaboration and manufacture of recyclable games and toys; and 4) Use with children aged 4 and 5 years. The results showed the scarcity of scientific publications on the subject as well as the potential and effectiveness of using games made with recyclable materials, in promoting environmental education with preschool children.
\end{abstract}

Keywords: Childhood; Play; Recycling; Extension.

\footnotetext{
* Professora da Universidade Estadual de Londrina (UEL), Londrina - PR, Brasil. E-mail: mfurlan@uel.br
}

** Professora da Universidade Estadual de Londrina (UEL), Londrina - PR, Brasil. E-mail: valeriauel@uel.br 


\section{Primeiras palavras: $o$ início de tudo}

Na infância bastava sol lá fora e o resto se resolvia.

(Fabrício Carpinejar)

A brincadeira por meio de jogos e brinquedos se constitui em uma das principais maneiras de a criança ser e se expressar na infância, de tal modo que se pode afirmar que a criança, sobretudo nos primeiros anos de vida, é, em grande medida, um ser brincante. Quando essa experiência acontece por meio da relação entre ludicidade e meio ambiente, seu efeito se torna mais significativo para a vida infantil, porque a criança pode vivenciar situações lúdicas por meio de jogos e brinquedos confeccionados com materiais recicláveis e, ainda, desenvolver potenciais enriquecedores para seu aprendizado e humanidade: habilidades cognitivas e psicomotoras, criatividade, imaginação, interação social, valores humanos e sociais, autoconhecimento e cidadania.

Relacionar a ludicidade com a educação ambiental pode ser considerado desafiador, especialmente no que se refere à ausência de conscientização e preservação do meio ambiente em virtude da produção excessiva de lixo no Planeta. Nesse seguimento, a reciclagem tornase uma estratégica consciente de devolver à natureza o que lhe foi tirado. Por meio de ações criativas e lúdicas, é possível reinventar e brincar pelas trilhas da reciclagem.

Assim, este relato se justifica como possibilidade de compartilhar experiências do Projeto de Extensão "Educação Ambiental e Infância: reflexões e ações a partir de jogos e brinquedos confeccionados com material reciclável", proposto pelo Departamento de Psicologia Social e Institucional e pelo Departamento de Educação da Universidade Estadual de Londrina (UEL), em sintonia com o Programa Universidade Sem Fronteiras (USF) e a Unidade Gestora do Fundo Paraná (UGF). O projeto foi desenvolvido nos anos de 2018 e 2019 e teve como objetivo principal oferecer suporte teórico e prático a profissionais de educação infantil de instituições filantrópicas e da rede pública de ensino de Londrina e região, por meio de um curso de extensão e formação continuada em Educação Lúdica, tendo como foco a educação ambiental e a confecção de jogos educativos com materiais recicláveis.

Para a realização dos propósitos do projeto, várias etapas de trabalho aconteceram. Neste texto, pretende-se descrever e analisar algumas ações condizentes ao processo de confecção e aplicação dos jogos e brinquedos com crianças de 4 e 5 anos, que frequentam um dos Centros de Educação Infantil público do Município de Londrina, Paraná. Para tal feito, o objetivo geral deste artigo é refletir sobre o processo de confecção e aplicação de jogos e brinquedos com materiais recicláveis por meio da interação com os estudantes de Psicologia e Pedagogia/Pibid da UEL.

A metodologia utilizada foi a pesquisa bibliográfica e a pesquisa de campo com observação-participante, a qual pautou-se nas seguintes etapas: 1) Organização do trabalho; 2) Preparação dos discentes (Psicologia e Pedagogia/Pibid); 3) Elaboração e confecção de jogos e brinquedos recicláveis; 4) Aplicação dos jogos e brinquedos com crianças de 4 e 5 anos pelos estudantes de Pedagogia/Pibid. Cabe salientar que os jogos e brinquedos foram 
elaborados e confeccionados pelos estudantes com uso de materiais recicláveis. Ainda, foram elaboradas duas fichas para avaliação do processo, a saber: a) ficha de avaliação de jogos e brinquedos confeccionados; b) ficha de avaliação da aplicação dos jogos com as crianças.

À vista do exposto, vale ressaltar que é necessário criar condições para o brincar infantil como um todo, desde o ambiente familiar ao espaço formativo e educacional da infância; é preciso, igualmente, tomada de consciência do valor insubstituível da ludicidade por meio da reinvenção e criação brincante pela criança e entre os pares.

\title{
Percurso metodológico: tempo de criar, brincar e aprender
}

\author{
As meninas do colégio no recreio brincavam do velho \\ e jamais esquecido brinquedo de roda \\ E eu, ali parada; olhando \\ Esquecida no chão a cesta com sua roupa de volta para mãe lavar \\ Tinha nos olhos e na atitude tal expressão, \\ tanto desejo de participar daquele brinquedo [...].
}

(Cora Coralina)

A metodologia desenvolvida no projeto, de natureza qualitativa, contou com uma pesquisa bibliográfica e de campo com observação participante. Neste artigo, pretende-se relatar o processo vivenciado pelos sujeitos envolvidos (professores, estudantes e crianças da educação infantil). Entre os estudos consultados, destacam-se os de Vygotsky $(1998,2010)$ Kishimoto (2002), Brasil (2018), Angotti (2007), entre outros, e a pesquisa de campo envolveu a participação de 17 crianças de 5 anos em fase pré-escolar. Por meio das atividades do projeto de extensão, foram delimitadas as ações relacionadas à análise, confecção e aplicação dos jogos e brinquedos recicláveis com as respectivas crianças. Visando compreender em profundidade alguns fenômenos da prática lúdica com crianças, essas etapas do projeto de extensão foram desenvolvidas nos anos letivos de 2018 e 2019.

O respectivo projeto desenvolveu-se com a participação quatro docentes, sendo três do Departamento de Psicologia Social e Institucional e um do Departamento de Educação, ambos da UEL. Dos quatros docentes, três participaram como orientadores e um como coordenador e orientador do projeto. Além dos docentes, houve a participação de sete estudantes do curso de Psicologia (quatro bolsistas e três colaboradores) e dez estudantes do curso de Pedagogia, na qualidade de colaboradores.

As atividades do projeto aconteceram em diferentes espaços da UEL, no Departamento de Psicologia Social e Institucional, na sala de aula e no Laboratório de Brinquedos e Jogos Educativos (LABBE). Além da universidade, a aplicação dos jogos e brinquedos foi realizada em um dos Centros de Educação Infantil público do Município de Londrina, que atende crianças de 0 a 5 anos de idade em período integral, filhos de 
funcionários dos órgãos/unidade do Hospital Universitário, local que, atualmente, oferece educação e cuidado a um número aproximado de cem crianças.

As etapas e procedimentos metodológicos sucederam-se da seguinte forma: 1) Organização do trabalho; 2) Preparação dos discentes (Psicologia e Pedagogia/Pibid); 3) Elaboração de material apostilado e confecção de jogos e brinquedos recicláveis; 4) Aplicação dos jogos e brinquedos com crianças de 5 anos pelos estudantes de Pedagogia/ Pibid. Cabe salientar que os jogos e brinquedos foram elaborados e confeccionados pelos estudantes com uso de materiais recicláveis.

Em se tratando da organização do trabalho, no primeiro momento foi realizada a instalação de material permanente, com o intuito de viabilizar a realização das atividades acadêmicas e reuniões com os estudantes e seus respectivos orientadores, foi instalada a impressora e o ar-condicionado no LABBE. Foi realizada, também, a ambientalização lúdica do espaço, pelos estudantes de Psicologia, por meio da organização e identificação dos jogos e brinquedos disponíveis no laboratório. Ainda, no segundo momento, foi possível desenvolver um planejamento e cronograma de trabalho, a fim de pensar as ações de forma coerente e condizente com os objetivos do projeto, o que, neste caso, foi deter-se às etapas de elaboração, confecção e aplicação dos jogos.

A preparação dos discentes de Psicologia e Pedagogia aconteceu por meio de reuniões entre orientadores e coordenação; orientadores e estudantes e, ainda, reuniões de estudo e discussão de textos relacionados ao brincar, jogos, brinquedos, infância e desenvolvimento, ludicidade. Para este estudo, buscou-se trilhar por um aporte teórico voltado a uma formação lúdica e humanizadora da infância, por meio de contribuições teóricas dos autores já supracitados. Nas reuniões de estudo, os participantes tiveram a oportunidade de compartilhar leituras e concepções complexas relacionadas à infância e suas formas brincantes de agir no mundo e com o mundo. Em linhas gerais, houve a sintonia do olhar sensível para o brincar infantil como atividade essencial para o desenvolvimento integral e aprendizagem da criança.

$\mathrm{Na}$ etapa de elaboração e confecção de jogos e brinquedos recicláveis, o intuito foi desenvolver nos estudantes, como formação inicial, a compreensão acerca da importância desse tipo de atividade lúdica com as crianças, sobretudo no que tange ao desenvolvimento da percepção tátil, visual, acuidade auditiva, organização espacial, coordenação motora, linguagem oral, expressão corporal e, ainda, estimular a prática de reciclagem como uma proposta alternativa para amenizar os impactos causados pelo descarte de certos materiais, como: garrafas pet, copos descartáveis, papelão, jornais e revistas velhas, entre outros. Quadros (2007) enfatiza que a reinvenção desses materiais recicláveis em jogos e brinquedos é uma das ações valiosas na educação e formação da humanidade das crianças, especialmente pelo fomento do pensar sustentável e da preservação do meio ambiente.

Nessa etapa, também foi realizada a interação entre orientadores, coordenador e estudantes, com a intenção de analisar e confeccionar jogos e brinquedos educativos por meio de diversos materiais de consumo e recicláveis. Além da confecção dos jogos, a proposta direcionou 
para a relação com as novas contribuições da Base Nacional Comum Curricular (BNCC), em especial no tocante aos campos de experiência na educação infantil (BRASIL, 2018).

Aconteceram atividades relacionadas à apresentação, análise e confecção de protótipos dos jogos e brinquedos; e a elaboração e avaliação dos protótipos por meio de um instrumento avaliativo - "ficha de avaliação de jogos e brinquedos confeccionados" - com questões objetivas relacionadas a: nome do jogo, faixa etária, objetivos, campo(s) de experiência, número de praticantes no jogo, materiais utilizados, descrição, fotografia, tempo de confecção e variação do jogo.

Após a avaliação dos jogos educativos por meio do instrumento, foram realizadas as modificações requeridas para sua melhor aplicação junto às crianças. Como resultado deste trabalho, foram criados e adaptados 18 brinquedos e/ou jogos educativos, contemplando todos os campos de experiência da EI propostos pela BNCC (BRASIL, 2018). E, por fim, foi elaborada uma apostila no intuito de descrever a confecção de cada um dos jogos, seus objetivos, regras e respectivas idades adequadas.

A última etapa referente à aplicação dos jogos e brinquedos com crianças de 5 anos pelos estudantes de Pedagogia/Pibid aconteceu em uma sala de pré-escola pública, que atende o número aproximado de 17 crianças em período integral. Em consonância com a participação no Projeto de Extensão, os estudantes do $2^{\mathrm{a}}$ ano do curso de Pedagogia também desenvolviam atividades de ensino, por meio da participação como bolsistas e voluntários no Pibid.

Desse modo, com base na elaboração do material apostilado e dos protótipos de jogos educativos, cada estudante teve a tarefa de confeccionar um jogo ou brinquedo em conformidade com, pelo menos, um dos campos de experiência proposto pelo documento normativo, no caso a BNCC. ${ }^{\text {ii }}$ Sequencialmente, foi realizada a interação e aplicação do jogo educativo com as crianças em dias alternados da semana, somando-se, ainda, com as demais atividades do Pibid. Para essa etapa, foi elaborada uma ficha de avaliação da aplicação dos jogos com as crianças. $\mathrm{Na}$ ficha, os critérios a serem analisados foram divididos em duas partes: 1) interesse e motivação das crianças; relevância do jogo; confiança ao jogar; satisfação da criança; experiência e conhecimento pela criança do jogo. 2) Autorreflexão: avaliação da ação do estudante na explicação e mediação durante o brincar da criança com o jogo educativo.

Os dados sobre a aplicação dos jogos foram registrados no diário de campo, imediatamente após a realização das atividades, para não haver perda de informações relevantes e detalhadas sobre o processo de aplicação dos jogos. Posteriormente, os dados foram sistematizados, organizados e analisados, viabilizando a reflexão sobre a formação e a ação docente como agentes educacionais. 


\section{Resultados e discussão: da reinvenção do brinquedo ao brincar criativo} Tenho a impressão de ter sido uma criança brincando à beira-mar, divertindo-me
em descobrir uma pedrinha mais lisa ou uma concha mais bonita que as outras,
enquanto o imenso oceano da verdade continua misterioso diante de meus olhos.

(Isaac Newton)

Em face do contexto atual, demarcado pelo sedentarismo produzido por meio dos grilhões da indústria cultural e do consumo de mercadoria em longa escala; pelo enquadramento ou disciplinamento do corpo à técnica e pela redução do brincar ao brinquedo tecnológico; pela ausência da experiência criativa, de expressividade e interação no mundo e com o mundo, é se que chega a esse momento tão importante, que é a socialização dos resultados (parciais) obtidos no projeto de extensão e as possíveis discussões de continuidade desse estudo e ação tanto na escola como fora dela.

Acreditando, desse modo, na premente necessidade do reconhecimento do brincar como manifestação criativa e inventiva de crianças, com vivências à luz de relações interativas e lúdicas é que se deve pensar sobre o lugar do brincar e do jogo e brinquedo reinventado por educadores e crianças nesse quintal contemporâneo.

São inúmeras as situações em que o brincar e a brincadeira incitam na criança o desejo de aprender, desenvolver e interagir entre pares, provocando a necessidade de resolver situações-problema e desafios e, em especial, potencializar o autoconhecimento. Nesse sentido, o jogo e o brinquedo, que podem ser confeccionados pelas próprias crianças em momentos lúdicos, não se constituem uma imposição e sim uma condição e necessidade da própria infância, como atividade criadora e de (re)construção do real (VYGOTSKY, 1998).

Segundo Cunha (2007), o jogo e o brinquedo são fundamentais para o desenvolvimento saudável do ser humano. Dessa forma, é importante que aconteça da maneira mais plena possível, de modo que qualquer criança tenha no brincar um elemento fundamental para aprender e se desenvolver integralmente. A esse respeito, Vygotsky (1998) assevera que os brinquedos e os jogos exercem um papel considerável no processo de desenvolvimento da criança, em conformidade com os seguintes elementos de aprendizagem: a) valores e habilidades psicomotoras; b) desenvolvimento de experiências criativas e simbólicas; c) elaboração de conceitos científicos; d) desenvolvimento afetivo e intelectual, experiências culturais e sociais, e autoconhecimento na qualidade de ser humano social.

Diante disso, os resultados obtidos em relação às etapas propostas demarcam que intenções e ações planejadas foram efetivas em relação ao objetivo principal, garantindo o brincar infantil por meio da promoção dos jogos e brinquedos educativos. De maneira ampliada, o olhar contextual dessa experiência extensionista volta-se para a credibilidade, por parte dos envolvidos, no brincar e na brincadeira como necessidades vitais da infância, para as quais são promovidas oportunidades à criança de aprender, interagir e ser feliz, independentemente de qualquer outra vantagem dessa atividade. 
No tocante à organização do trabalho e preparação dos discentes, observou-se que, além de subsidiar no campo teórico e prático, houve a promoção da interação entre os estudantes dos cursos de Psicologia e Pedagogia da UEL, por meio de ações relacionadas a ensino, pesquisa e extensão. Essa interação foi constatada em momentos de trocas de experiências, leituras, estudos, discussões, análises de materiais, produções de jogos e materiais didáticos, interação entre os próprios estudantes e entre estudantes e docentes, contribuindo efetivamente para o aprimoramento do saber e do conjunto de experiências via conhecimento e, consequentemente, para a formação inicial tanto do psicólogo quanto do pedagogo. Nessa perspectiva, Larrosa $(2018$, p. 22) revela que a experiência é uma forma de vida em que o conhecimento se faz "corporalizado, incorporado, encarnado", ou seja, o conhecimento da experiência é o conhecimento prático, derivado de uma relação ativamente comprometida com o mundo.

$\mathrm{Na}$ etapa de elaboração e confecção de jogos e brinquedos recicláveis, foram realizadas algumas ações pelos estudantes, entre as quais uma pesquisa bibliográfica nos periódicos da Coordenação de Aperfeiçoamento de Pessoal de Nível Superior (CAPES), dos últimos dez anos, com o objetivo de localizar publicações relacionadas à confecção de jogos e brinquedos com materiais recicláveis e o seu respectivo uso na educação infantil. A classificação de periódicos selecionada abrangeu todas as revistas qualificadas, inseridas nos periódicos do quadriênio de 2013-2016, contemplando as áreas de Educação e Psicologia.

Foram realizadas buscas em sites internacionais e no Portal de Periódicos e Livros da CAPES com a finalidade de selecionar publicações que abordassem como a educação ambiental vem sendo trabalhada mundialmente na educação infantil. Além disso, entrou-se em contato com diversas instituições no exterior, a fim de obter informações sobre projetos e demais ações no campo da educação ambiental, inclusive a instituição italiana Reggio Emília, que é referência mundial em educação infantil. Contudo, nessa busca não se constatou o uso de jogos confeccionados com materiais recicláveis como recurso na educação ambiental, mas sim produções voltadas para a criação de jogos na educação infantil.

A pesquisa realizada evidenciou a escassez de publicações científicas sobre educação ambiental na educação infantil, por meio do uso de jogos e brinquedos confeccionados com materiais recicláveis. Em contraposição, foram identificadas evidências notórias sobre a importância da prática lúdica com jogos, brinquedos e brincadeiras para a aprendizagem e desenvolvimento integral das crianças na educação infantil. Assim, o espaço e o momento do brincar precisam, por excelência, ser um lugar/tempo privilegiado no trabalho pedagógico e educativo com crianças.

$\mathrm{Na}$ etapa referente à confecção e adaptação de jogos educativos com uso de material reciclável, foi proposto que os discentes criassem ou adaptassem brinquedos ou jogos educativos com materiais recicláveis. Com este propósito, foi realizada uma pesquisa e seleção de jogos e brinquedos que pudessem ser adaptados para a educação infantil, utilizando-se de materiais recicláveis. Sequencialmente, foi feita a apresentação, análise e 
confecção de protótipos dos brinquedos ou jogos educativos com materiais recicláveis para serem posteriormente aplicados com as crianças pré-escolares, no caso em pauta.

Foram confeccionados 18 brinquedos e jogos educativos com materiais recicláveis, em conformidade com a faixa etária das crianças da educação infantil. Esses brinquedos e jogos foram descritos em suas etapas e organizados em formato de uma apostila. Para cada jogo confeccionado, foi estabelecido o objetivo, os procedimentos para jogar/brincar e os conteúdos explorados de acordo com os campos de experiência estabelecidos pela BNCC (BRASIL, 2018). Esta apostila foi organizada com o objetivo de ser um suporte teóricometodológico para os professores em processo de formação inicial e continuada, acerca do trabalho com os jogos infantis.

Posteriormente, esses jogos confeccionados passaram por uma avaliação prévia pelos estudantes de Psicologia, Pedagogia e os respectivos professores vinculados ao projeto, com o objetivo de analisar e avaliar a qualidade da confecção e sua possível aplicabilidade junto às crianças da pré-escola, em diálogo com os campos de experiência.

Isso se justifica ao se considerar que, na educação infantil, as aprendizagens essenciais compreendem tanto comportamentos, habilidades e conhecimentos quanto vivências que sejam promotoras de aprendizagem e desenvolvimento nos chamados campos de experiência, sempre levando em consideração as interações e a brincadeira como eixos estruturantes desse processo formativo da criança (BRASIL, 2018).

A ficha avaliativa (elaborada por todos os envolvidos no projeto) considerou os seguintes elementos de ordem objetiva: a) nome do jogo ou brinquedo; b) objetivo; c) faixa etária; d) número de participantes; e) campos de experiência; f) componentes do jogo e materiais utilizados; g) confecção e imagem fotográfica do jogo; h) regras e seus desdobramentos. Como questão subjetiva, houve a possibilidade de indicar sugestões sobre os jogos avaliados, apresentando ideias e dicas para melhoria e ampliação do jogo/brinquedo confeccionado, bem como de sua descrição.

A avaliação prévia foi realizada pelos estudantes de Pedagogia e pela professora orientadora, os quais, em etapa de escolha de um dos jogos, puderam confeccionar e avaliar as informações organizadas pelos discentes de Psicologia em formato de Apostila. Para esse fim, os jogos escolhidos foram: 1) O que é?; 2) Bolinhas matemáticas; 3) O primeiro a chegar; 4) Tapete do movimento; e 5) Memosom.

De maneira sintética, as etapas foram desenvolvidas abarcando todos os participantes do projeto. Desse processo, inferiu-se que a culminância das etapas com a aplicação dos jogos com as crianças reflete as intencionalidades concretizadas de maneira significativa e comprometida com a infância lúdica e consciente. As atividades do projeto de extensão puderam ser articuladas com as propostas de formação inicial docente relacionado ao Projeto de Ensino e Pesquisa intitulado Pibid/UEL.

Com relação à aplicação dos jogos e brinquedos com crianças pré-escolares, a experiência aconteceu por meio da participação dos estudantes de Pedagogia em consonância 
com as atividades do Pibid/UEL. Esse processo formativo permitiu aos estudantes a compreensão acerca das providências necessárias para que se concretize a experiência do brincar infantil, tais como: preparação do ambiente e do brinquedo/jogo; adequação do(s) espaço(s) para a brincadeira, bem como a promoção do ambiente lúdico e desafiador mediado pelos educadores (em formação e/ou formados), nas situações brincantes de crianças. Ainda, permitiu aos envolvidos no projeto reconhecer o papel do professor no processo de elaboração, planejamento e confecção das atividades, bem como na seleção dos materiais lúdicos e no direcionamento das brincadeiras.

De maneira ampla, os estudantes puderam avaliar a importância do contexto pedagógico e dos ambientes educativos destinados às atividades do brincar, devendo ser fisicamente estruturados de modo a garantir que a criança aprenda e se desenvolva integralmente nos momentos lúdicos. Em contrapartida, segundo Vygotsky (1998), cabe ao educador, como um adulto social mais experiente, incentivar as crianças a brincar, organizar o espaço físico da escola (interno e externo), facilitando a disposição dos brinquedos, mobiliário etc., ou ainda, potencializar um ambiente em que a experiência infantil seja enriquecida por enlaces emocionais e fantasias.

Diante disso, cabe relatar a seguir alguns pontos significativos envolvendo a aplicação dos jogos com as crianças pelos estudantes, que no caso desenvolveram a ação em dupla. Ao todo, foram cinco duplas responsáveis pela aplicação de cinco jogos. Desse modo, tomandose por base os jogos, serão indicados pontos de aprendizagem e reflexão para a possível contribuição no campo formativo docente.

Com relação aos jogos, propõe-se uma breve descrição de seus objetivos, faixa etária, regras e campos de experiência desenvolvidos. O jogo "O que é?" objetiva levar a criança a fazer uma associação dos sentidos (audição, olfato, tato e paladar) com as figuras do tabuleiro. Pode ser desenvolvido com crianças entre 4 e 5 anos de idade e contempla todos os campos de experiência da BNCC ${ }^{\text {iii }}$. As regras do jogo se concentram em dividir a turma em dois grupos. Cada criança deve pegar uma ficha virada e levar até o seu grupo. Quando todas estiverem com suas fichas e grupos formados, o professor deverá realizar a seleção dos sentidos (audição, olfato, tato e paladar) de modo alternado.

Caso seja selecionado o sentido audição, o professor deve oferecer para a turma barulhos (seja por imitação, utilização de objetos que emitam sons ou os próprios sons oferecidos em um aparelho de rádio e/ou celular) das figuras representadas no tabuleiro. Assim, o grupo que possuir a ficha correspondente ao som e localizar a figura no tabuleiro ganha a jogada. No que concerne à aplicação do jogo, os estudantes avaliaram que ele é de grande relevância no processo de desenvolvimento cognitivo e interativo de crianças, uma vez que elas se sentiram atraídas para brincar. De início, as crianças demonstraram estranhamento diante do conceito relacionado aos "sentidos", sobretudo por associarem ao conceito de "sentimento". Houve, então, a necessidade de explicar a respeito do significado de cada palavra, para, assim, desenvolver a brincadeira. Após a leitura das regras e explicações sobre o jogo, a mediação dos educadores (dupla) ocorreu por meio de 
esclarecimentos, incentivos e promoção de situações desafiadoras e motivadoras para as crianças de maneira rica, alegre e interativa (Figura 1).

Figura 1: Jogo: O que é?
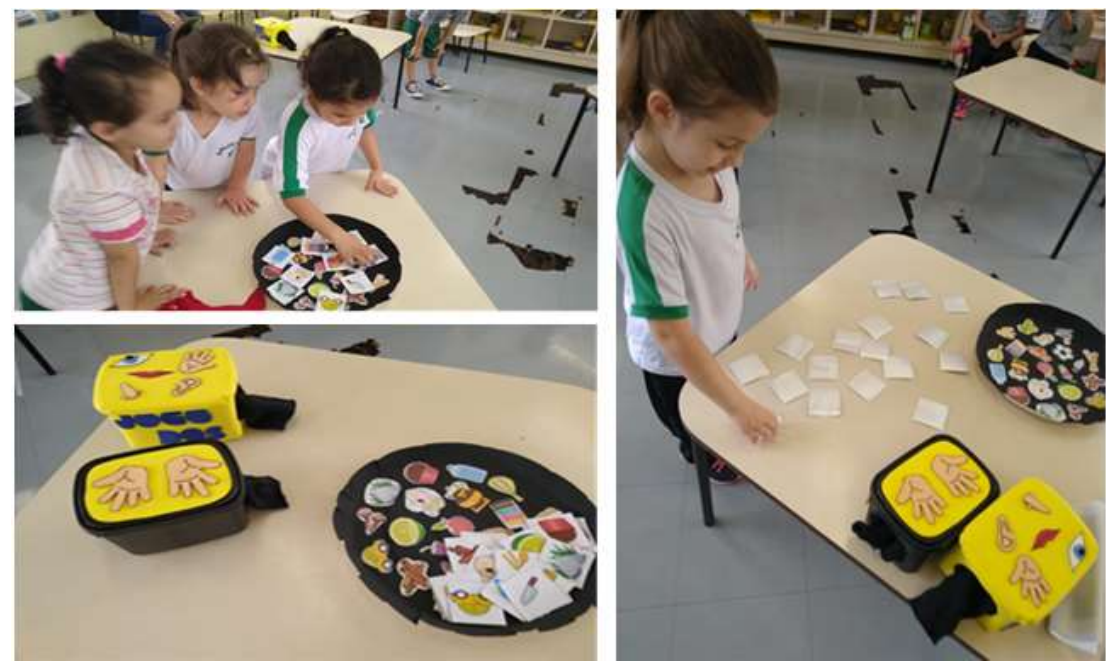

Fonte: Acervo pessoal.

No tocante à aplicação do jogo, de modo geral, as crianças demonstraram interesse e motivação para brincar, embora tenham apresentado um pouco de dificuldade, no início, para entender as regras do jogo. As crianças realizaram a brincadeira com mediação, demonstrando pouca satisfação durante a realização do jogo que, nesse caso, foi complexo para o seu nível de desenvolvimento. Quanto às interações, esperava-se que houvesse mais cooperação e envolvimento entre as crianças, o que aconteceu de maneira tímida nesse jogo. Ainda, de maneira geral, o jogo foi provocador de aprendizagem nas crianças, visto que puderam aprender conceitos e novas palavras e sentidos para o que está ao seu redor.

O segundo jogo aplicado foi "bolinhas matemáticas", cujo objetivo consiste em encaixar os rolinhos e inserir as bolinhas na caixa por meio da associação entre a quantidade e o número correspondente. Essa brincadeira pode ser desenvolvida com crianças a partir de 5 anos e explora os seguintes campos: Espaços, tempos, quantidades, relações e transformações; O eu, o outro e o nós.

Inicialmente, a aplicação do jogo se mostrou como um grande desafio para as crianças, em especial por envolver as operações matemáticas e os sinais de "soma" e de "igual". 
Figura 2: Jogo: Bolinhas matemáticas

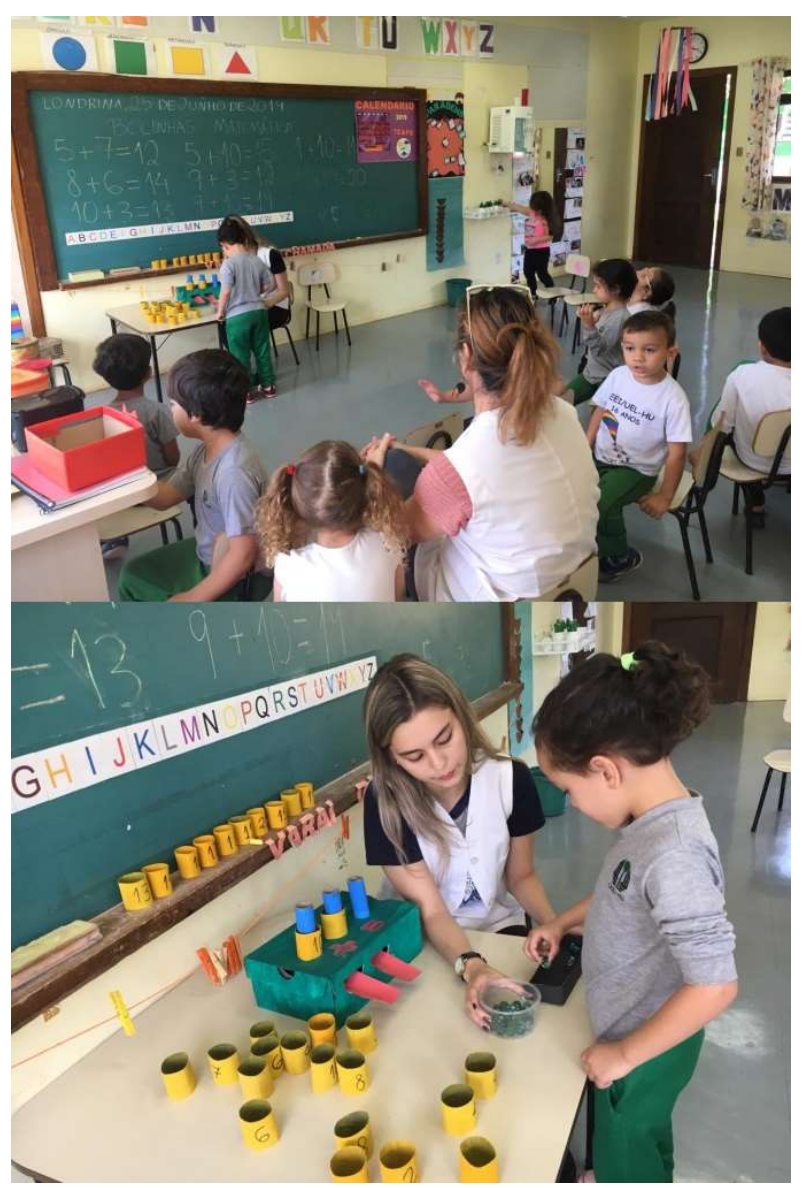

Fonte: Acervo pessoal.

Para a aplicação do jogo, foi preciso, inicialmente, ensinar os respectivos sinais $+\mathrm{e}=$, a fim de que as crianças pudessem brincar e, ainda, o significado matemático de cada sinal. Sobre isso, foi possível constatar que, para a fase pré-escolar, essa linguagem matemática está fragilizada no aprendizado das crianças, considerando a necessidade de melhorar a mediação docente sobre esses conceitos. Um dos estudantes relatou que foi preciso "usar os dedos das mãos para fazer uma analogia com a operação matemática do jogo”. Ainda, foi necessário deixar claro para as crianças que o objetivo do jogo era contar utilizando bolinhas, mas que é possível utilizar a contagem de outras formas e em diversas situações. Como foi perceptível a ausência dos conceitos matemáticos supracitados, os estudantes mediaram o jogo, incentivando a contagem das "bolinhas" em voz alta pelas crianças, a fim de que todas pudessem atentar-se para a brincadeira, além de ser uma forma de interação e motivação lúdica das crianças (Figura 2). 
Nesse prisma, salienta-se a necessidade de ressignificação do trabalho pedagógico pré-escolar, em consonância com a linguagem matemática direcionada para essa faixa etária do desenvolvimento. De acordo com a BNCC (BRASIL, 2018), no processo de ensino e aprendizagem matemática a ser promovido em sala pré-escolar, o professor necessita assegurar às crianças a mobilização de conhecimentos (conceitos e procedimentos), habilidades (práticas cognitivas e socioemocionais), atitudes e valores para resolver demandas complexas da vida cotidiana, do pleno exercício da cidadania e do mundo do trabalho.

Cabe à educação infantil e ao professor assegurarem os direitos de aprendizagem e desenvolvimento via competências gerais e, no caso do trabalho matemático e lúdico, é preciso estimular socialmente a criança para o exercício da curiosidade intelectual, incluindo a investigação, reflexão, análise crítica, imaginação, criatividade, o pensamento lógico, a fim de investigar causas, elaborar e testar hipóteses, formular e resolver problemas visando à criação de possíveis soluções (BRASIL, 2018).

O terceiro jogo, "O primeiro a chegar", tem como objetivo principal percorrer o tapete de peças quadradas e coloridas de papelão e chegar até o final (Figura 3). Para iniciar o jogo, cada participante joga o dado, com seis cores distintas (amarelo, azul, vermelho, verde, marrom e branco), e se posiciona na frente da fileira de quadrados com a cor correspondente a que saiu no dado, exceto as cores marrom e branca. O dado é jogado inicialmente pelo participante que ficará posicionado na cor estabelecida para compor a primeira fileira da esquerda para a direita. $\mathrm{O}$ educador jogará o dado e andará uma casa aquele que estiver na fileira da cor sorteada no dado. Sempre que for sorteada a cor marrom, todos os jogadores andarão uma casa, e quando for sorteada branca, todos os jogadores voltarão uma casa.

Vence o jogo aquele que chegar primeiramente ao final de sua fileira de quadrados coloridos. Esse jogo pode ser aplicado a partir de 3 anos de idade e envolve os seguintes campos de experiência: Corpo, gestos e movimentos; Traços, sons, cores e formas; $\mathrm{O}$ eu o outro e o nós; e, Espaços, tempos, quantidades, relações e transformações. A Figura 3 representa o momento da brincadeira, a qual foi bem recebida pelas crianças. Em se tratando dos jogos, esse foi um dos mais solicitados pelas crianças para que continuassem brincando, mesmo depois de concluírem o tempo do brincar. Com relação ao material, os estudantes avaliaram que as crianças ficaram bastante entusiasmadas com o dado, entretanto, o material utilizado na elaboração do objeto prejudicou um pouco esse momento, por dois fatores: 1 . $\mathrm{O}$ material utilizado foi frágil, visto que optaram por papelão; 2. O tamanho do dado também deixou a desejar, pois precisaria de um tamanho maior e proporcional ao ambiente e ao número de crianças participantes.

Diante desta avaliação do material, constatou-se que houve, por parte dos estudantes, uma tomada de consciência sobre esses processos de planejamento e confecção do jogo, entretanto, o interessante foi que, independentemente do material do jogo, a brincadeira aconteceu de maneira alegre, divertida e cheia de descobertas. 
Figura 3: O primeiro a chegar
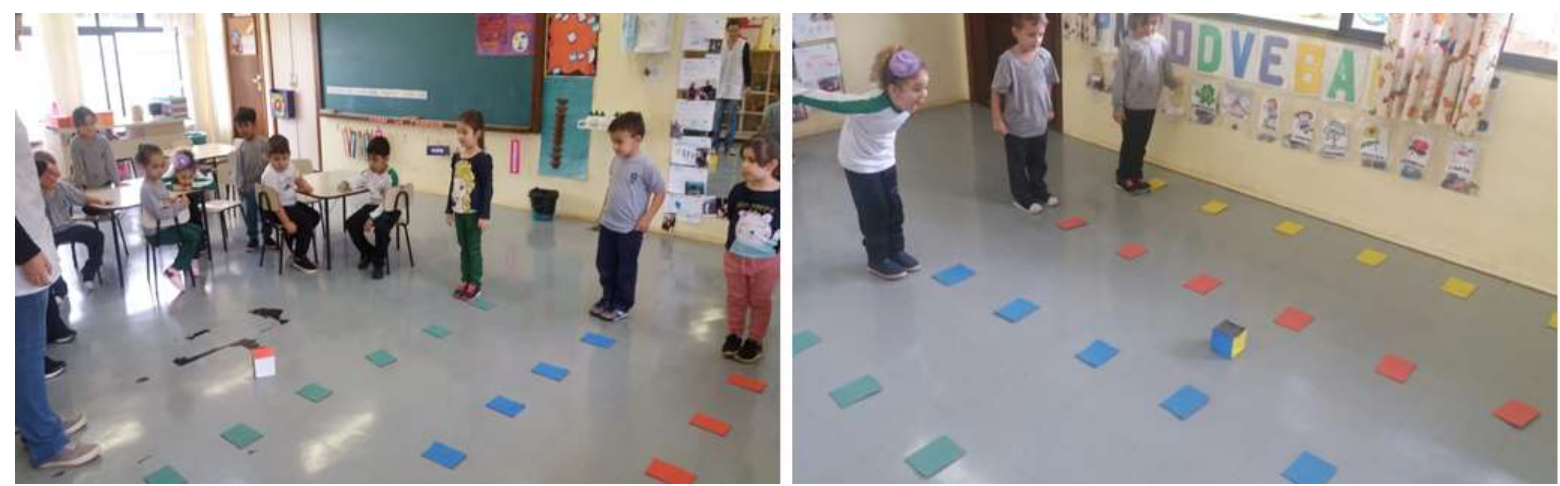

Fonte: Acervo pessoal.

O quarto jogo a ser aplicado foi o "Tapete do movimento" (Figura 4), promotor da brincadeira com o corpo e os movimentos, que pode ser aplicado com crianças a partir dos 3 anos e objetiva realizar o percurso do tapete mantendo-se o equilíbrio no movimento. Potencializa os seguintes campos: Corpo, gestos e movimentos; Traços, sons, cores e formas

Figura 4: Tapete do movimento
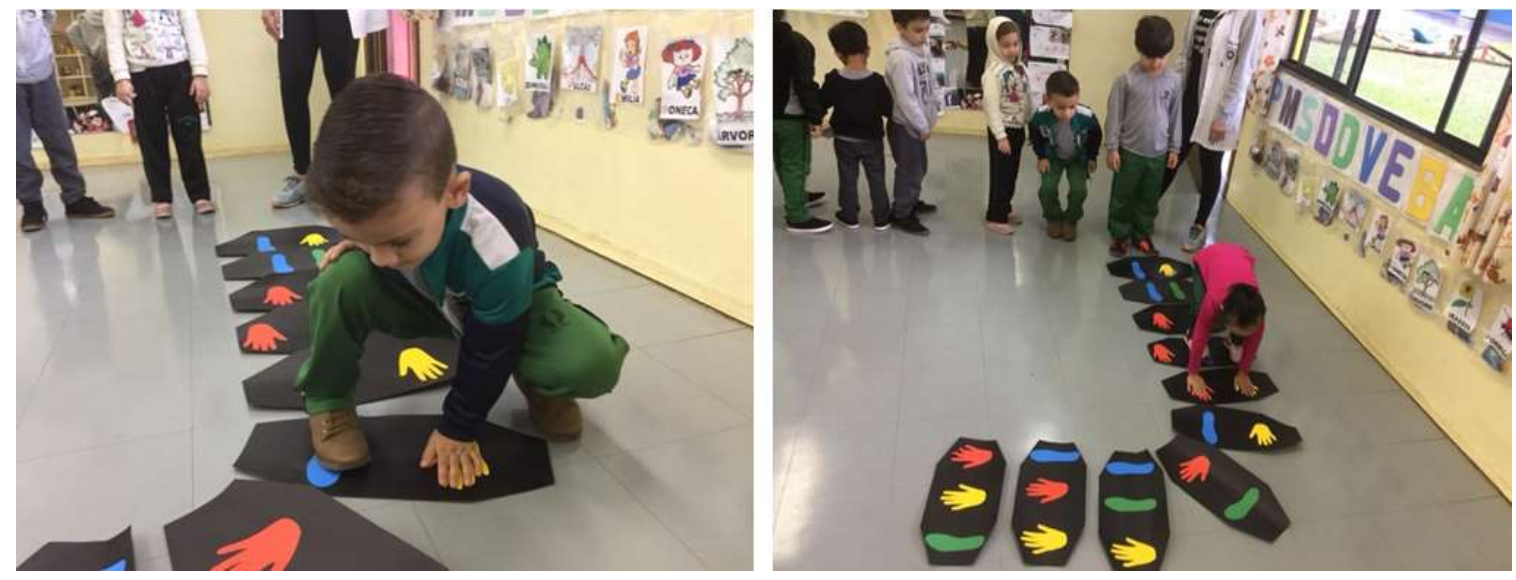

Fonte: Acervo pessoal.

Cabe observar que a brincadeira aconteceu dentro da sala de aula, a pedido da professora regente, considerando que, na parte externa, as crianças ficam dispersas. A esse respeito, é importante mencionar que a adequação do espaço e ambiente ao jogo potencializa 
o interesse e envolvimento das crianças (KISHIMOTO, 2002). Talvez, se a experiência tivesse sido na parte externa, no caso, na quadra ou pátio, as crianças poderiam ter se interessado mais pela proposta.

Com relação à aplicação do jogo, constatou-se que, de modo geral, as crianças ficaram interessadas pela brincadeira, entretanto, houve a necessidade de mediação e incentivo durante todo o processo, com o intuito de envolver as crianças no jogo sem que se prendessem em outra atividade dentro da sala, como brinquedos pedagógicos, giz de cera e papel, massa de modelar.

No tocante à compreensão das regras do jogo, ficou nítida pelas crianças, embora apresentassem pouca autonomia para cumpri-las. As falas das crianças envolviam frases do tipo: "Professora, eu não sei brincar" ou "Professora, brinca junto comigo?" ou "Quero jogar com você, professora". Nesse momento, a relação afetiva com os estudantes de Pedagogia também foi potencializadora da brincadeira, uma vez que as crianças queriam ficar perto deles e brincar com eles o tempo todo. A aprendizagem do jogo foi satisfatória; contudo, percebeu-se que esse conteúdo do jogo foi associado a outro que já conheciam, em virtude de outra brincadeira parecida desenvolvida pela professora regente, o que demandou dos discentes o desenvolvimento de estratégias que pudessem ser recompensadoras e estimulantes.

E, por fim, o jogo "Memosom" (Figura 5), que, de certa forma, foi bem atrativo para as crianças, especialmente por estimular a linguagem dos movimentos e expressões corporais. Esse jogo objetiva lembrar e imitar o som e os movimentos dos animais na sequência das cartas retiradas. Pode ser desenvolvido com crianças a partir de 4 anos e envolve os seguintes campos: Corpo, gestos e movimentos; Traços, sons, cores e formas; $\mathrm{O}$ eu, o outro e o nós.

Figura 5: Jogo: Memosom
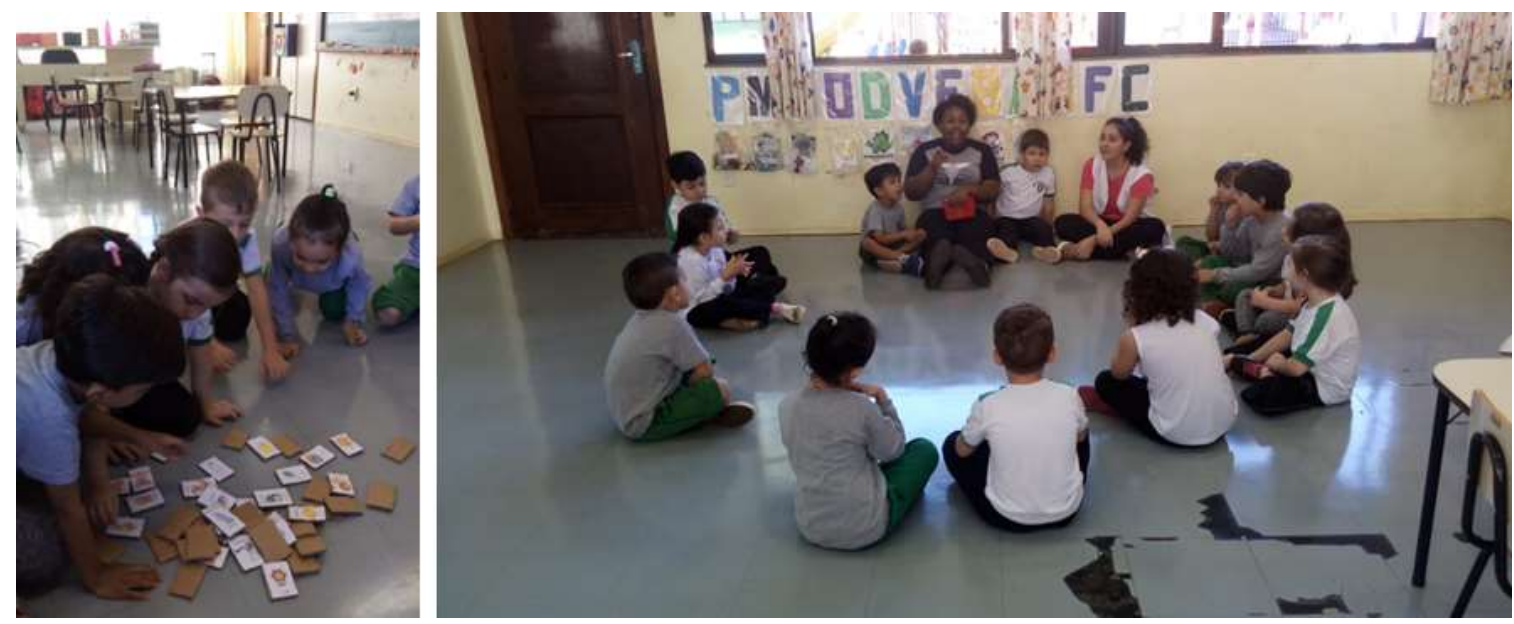

Fonte: Acervo pessoal. 
Em alguns momentos, foram feitas adaptações na representação mímica da palavra sorteada, sendo acrescentada a possibilidade de uso do som para representar os animais. Assim, com movimentos e, em alguns casos, sons, as crianças representavam o animal sorteado, incentivando as demais a descobrirem. De modo geral, houve boa participação das crianças durante a brincadeira e demonstração de satisfação ao realizarem o jogo, sobretudo no que se refere à aprendizagem e aos desafios enfrentados na brincadeira.

Em se tratando especificamente da Autorreflexão e avaliação da ação do estudante, na explicação e mediação durante o brincar da criança com o jogo educativo, foi possível constatar que há muito a ser aprimorado e aperfeiçoado, evidenciando a relevância da formação dos educadores para as mudanças conceituais e atitudinais, assim como a conscientização dos próprios educadores sobre a importância da mediação nas atividades lúdicas.

Nesse sentido, atenta-se para a necessidade de uma proposta de formação de professores que priorize o incentivo do ensino e de experiências brincantes de aprendizagem, distanciando-se do trabalho educativo movido por modelos escolarizantes e de prontidão para a alfabetização, ou seja, fragmentados e mecanizados. Por ser essa a tarefa do professor, tão fundamental na constituição da pessoa, é que se deve lutar para ter profissionais qualificados que ampliem seus saberes e fazeres docentes, com o propósito de potencializar o acontecimento das máximas possibilidades do desenvolvimento humano, ou seja: "[...] o meio desempenha no desenvolvimento da criança, no que se refere ao desenvolvimento da personalidade e de suas características específicas ao homem, o papel de fontes de desenvolvimento" (VYGOTSKY, 2010, p.682).

Faz-se necessário, portanto, que os diferentes profissionais que atuam nas instituições educativas valorizem a formação inicial e continuada, visando ao estudo e aprimoramento de aspectos imprescindíveis à sua ação pedagógica, a fim de desenvolver ações de mediação como possibilidade de ensino no processo de apropriação e internalização dos conhecimentos necessários à estimulação do desenvolvimento da criança desde a mais tenra idade. Vale ressaltar que a própria experiência pedagógica oportuniza a esse aprimoramento um ambiente dialógico, em que o aprender a confeccionar jogos recorda experiências e engendra novos sentidos e vivências emocionais com o ensinar.

Nesse prisma, os resultados fomentam novas discussões no campo formativo lúdico, no intuito de favorecer, por meio de vivências lúdicas, a construção/reconstrução do conhecimento acerca da ludicidade e aprendizagem infantil, utilizando como alternativa pedagógica os jogos no ambiente educacional que visem a mudanças nos modos de sentir, pensar e agir, buscando favorecer um clima motivacional que promova um ambiente de descoberta, interação e ludicidade. Ainda, capacitar e instrumentalizar, por meio de atividades extensionistas, os estudantes em formação e o profissional de educação infantil para a confecção de jogos educativos com materiais recicláveis. Ações relacionadas com a pesquisa sobre a importância do lúdico no 
processo de desenvolvimento e aprendizagem infantil se faz urgente, com a finalidade de compartilhar possibilidades inovadoras e conscientes sobre o brincar na infầncia.

O relatório de atividade de Madalena Freire, em fevereiro e março de 1978 (FREIRE, 1983), já afirmava que o trabalho do professor precisa ser pautado em uma ação intencionalmente planejada, a fim de que, por intermédio do brincar e aprender, as crianças se descubram participantes desse processo. $\mathrm{O}$ documento acrescenta, ainda, que:

É importante desde logo salientar que, de maneira alguma, esta rotina é vivida de modo rígido, inflexível, durante o decorrer do dia. Muitas vezes as próprias crianças propõem a sua inversão, ou a professora, baseando-se na observação do grupo, propõe um outro tipo de encaminhamento para o dia, dentro ou não da rotina. (FREIRE, 1983, p. 19).

Nessa perspectiva, será possível garantir os direitos de aprender de maneira alegre, ativa e brincante, somente quando se pensar criticamente acerca da qualidade da formação dos professores que atuam com as crianças desde a educação infantil, uma vez que se torna a linha diretriz para qualquer ação educativa com as crianças. A formação, nesse sentido, é o ponto essencial que estrutura e implementa as demais variáveis que compõem o conceito de qualidade do trabalho pedagógico na escola da infância (ANGOTTI, 2007).

É uma tarefa complexa e difícil, mas não impossível, pois, se o professor considerar o conhecimento sobre a infância e o brincar como o eixo central de seu trabalho, com o intuito de encontrar nos pressupostos teóricos a liberdade para suas escolhas intencionais, ele encontrará as brechas para a efetivação de uma ação pedagógica profícua. Assim como o tempo, o espaço também deve ser organizado, levando-se em conta o objetivo de promover o desenvolvimento integral das crianças. Horn (2004, p. 15) orienta a pensar sobre essa questão ao escrever:

\footnotetext{
O olhar de um educador atento é sensível a todos os elementos que estão postos em uma sala de aula. O modo como organizamos materiais e móveis, e a forma como crianças e adultos ocupam esse espaço e como interagem com ele são reveladores de uma concepção pedagógica. Aliás, o que sempre chamou minha atenção foi a pobreza frequentemente encontrada nas salas de aula, nos materiais, nas cores, nos aromas; enfim, em tudo que pode povoar o espaço onde cotidianamente as crianças estão e como poderiam desenvolver-se nele e por meio dele se fosse mais bem organizado e mais rico em desafios.
}

Há a necessidade de se criar condições ricas e diversificadas para que cada criança trilhe seu caminho e promova o máximo desenvolvimento, com o propósito de respeitar as diferenças sem perder a visão da totalidade do ensino. Para isso, o trabalho humanizado e compartilhado entre professores e crianças e entre crianças e crianças pode direcionar para $\mathrm{o}$ universo da descoberta. 


\title{
Palavras finais: a reinvenção lúdica que gera experiência
}

\author{
[...] é condição da experiência [...] estar imerso no mundo que \\ chega a nós, que nos envolve, que nos compromete ou, às vezes, exige de \\ nós ou nos impõe. \\ (Lara e Contreras, 1997).
}

Ao se refletir sobre a educação ambiental e lúdica na educação infantil e o processo formativo docente, entende-se que é necessário delinear novos caminhos, no intuito de obter uma ação pedagógica de maior qualidade. Para tanto, é essencial privilegiar discussões pautadas em fundamentos teórico-práticos sobre a ação docente, visando a uma melhor compreensão acerca do assunto.

Entretanto, para que esta prática seja implementada, é preciso que o educador, em primeiro lugar, amplie sua aprendizagem, por meio de situações práticas, exigindo o desenvolvimento de uma atuação reflexiva competente, promovendo a conexão entre a formação inicial, a continuada e as experiências vividas entre pares. Para tanto, além de orientações para a construção de jogos e brinquedos, é necessária a reflexão sobre a importância de aliar a ludicidade à educação ambiental, para que haja a concretização dos objetivos propostos.

Sendo assim, a proposição e o uso de jogos e brinquedos confeccionados com materiais recicláveis nesse projeto se justificam como uma opção economicamente viável, aliada à responsabilidade socioambiental, que propicia aprendizado sobre educação ambiental, estimula a coleta seletiva e possibilita aos professores e crianças que se conscientizem sobre a importância de participar da preservação do meio ambiente. Isso faz com que desenvolvam o senso de responsabilidade individual e coletiva, a cooperação, além de sensibilizá-los para a confecção do brinquedo construído em detrimento do brinquedo pronto e tecnológico.

De forma geral, a participação no projeto de extensão mencionado potencializou a formação inicial e continuada de estudantes e professores, visto que, por meio da compreensão crítica do brincar, ressignificado pela confecção de jogos com uso de materiais recicláveis, pôde-se constatar a presença, ainda, de um entendimento superficial em relação à educação ambiental e o uso de jogos e brincadeiras recicláveis com crianças.

Nesse prisma, se as práticas pedagógicas que compõem a proposta curricular da Educação Infantil devem ter como eixos norteadores as interações e a brincadeira, assim como devem promover a imersão das crianças em diferentes linguagens, formas de expressão e vivências, por que não ensinar a educação ambiental por meio de recursos lúdicos, utilizandose de jogos e brinquedos confeccionados com materiais recicláveis, sobretudo como lugar de ressignificação ao que está posto pela escola como fonte inspiradora do brincar?

Por conseguinte, é preciso garantir o direito da criança a uma educação lúdica, interativa e democraticamente de qualidade. Para isso, é necessário fomentar situações em que os pequenos possam brincar com outras crianças por meio do brincar construído, 
espontâneo, dirigido, e que haja a convivência entre crianças mediada por situações envolvendo o respeito às diversas formas de cultura e regras sociais. Nesse sentido, ao se fazer referência a conviver, pretende-se revelar uma educação infantil que pense no outro, que esteja para o outro e pelo o outro.

Assim sendo, é essencial planejar, organizar e executar ações concretas para transformar a educação infantil, torná-la prazerosa, alimentando o desejo da criança por conhecer e experienciar o mundo que a cerca. A utilização de jogos na prática docente requer a compreensão das suas potencialidades educacionais e a reflexão a respeito de seu próprio trabalho, bem como sua função no processo de ensino-aprendizagem de questões ambientais.

Portanto, é necessário que o educador reconheça seu papel de representante de práticas culturais, valores e crenças que podem contribuir para um mundo mais sustentável. Neste sentido, o projeto de extensão desenvolvido e que se apresentou de forma parcial neste texto forneceu subsídios teórico-metodológicos significativos e emancipatórios no processo de reconhecimento sobre a importância do lúdico no desenvolvimento de ações de educação ambiental e lúdica, como também sua função no desenvolvimento integral da criança, bem como na formação de sua humanidade.

\section{Referências}

ANGOTTI, M. Projeto de pesquisa de educação infantil: elegendo e analisando critérios para se investir na qualidade do atendimento. Araraquara: Unesp, 2007. (Relatório de Atividades, Proposta Complementar de Pesquisa para o Triênio).

BRASIL. Ministério da Educação. Base Nacional Comum Curricular: Educação é a Base. Brasília, DF: MEC/CONSED/UNDIME, 2018.

CUNHA, N. H. S. Criar para Brincar. São Paulo: Aquariana, 2007.

FREIRE, M. A paixão de conhecer o mundo: relatos de uma professora. 9. ed. Rio de Janeiro: Paz e Terra, 1983.

HORN, M. G. S. Sabores, cores, sons, aromas: a organização dos espaços na Educação Infantil. Porto Alegre: Artmed, 2004.

KISHIMOTO, T. M. (org.). O brincar e suas teorias. São Paulo: Pioneira Thomson Learning, 2002.

LARA, N. P.; CONTRERAS, J. Investigar la experiência educativa. Paris: Seuil, 1997. 
LARROSA, J. Esperando não se sabe o quê: sobre o ofício de professor. Tradução de Cristina Antunes. Belo Horizonte: Autêntica, 2018. (Coleção Educação: Experiência e Sentido).

QUADROS, A. de. Educação ambiental: iniciativas populares e cidadania. 2007. 46 f. Monografia (Especialização em Educação Ambiental) - Universidade Federal de Santa Maria, Santa Maria, 2007.

VYGOTSKY, L. S. O desenvolvimento psicológico na infância. Rio de Janeiro: Martins Fontes, 1998.

VYGOTSKY, L. S. Quarta aula: a questão do meio na pedologia. Psicologia USP, São Paulo, v. 21, n. 4, p. 681-701, set./dez. 2010.

\footnotetext{
Notas

${ }^{i}$ Especificamente os estudantes do curso de Pedagogia, concomitante à participação no Projeto de Extensão, também estavam vinculados ao Programa Institucional de Bolsa de Iniciação à Docência (Pibid/UEL), assim, dos dez participantes, sete eram bolsistas e três voluntários.

ii Educação infantil e os campos de experiência: Eu, o outro e o nós; Corpo, gestos e movimento; Traços, sons, cores e formas; Escuta, fala, pensamento e imaginação; Espaços, tempos, quantidade, relações e transformações (BRASIL, 2018).

iii Campos de Experiência: O eu, o outro e o nós; Traços, sons, cores e formas; Corpo, gestos e movimentos; Espaços, tempos, quantidades, relações e transformações; Escuta, fala, pensamento e imaginação (BRASIL, 2018).
} 